\title{
Diet, shopping and food-safety skills of food stamp clients improve with nutrition education
}

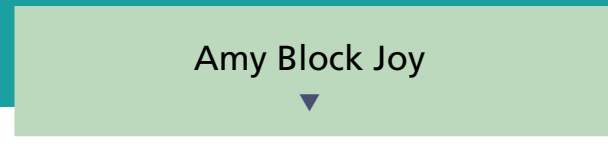

The California Food Stamp Nutrition Education Program (FSNEP) reaches approximately 50,000 families with children and individuals annually. Results from the 2001-2002 fiscal year demonstrated improvements in a variety of dietary and foodsafety skills after clients received FSNEP training. In addition, results from a subsample $(n=460)$ showed significant improvements in the amount of money saved on food purchases, along with improved dietary quality. FSNEP provides food stamp clients with needed nutrition skills and promotes behavioral change to help them stretch limited resources. Program management practices have had positive effects on the program's overall operation and growth.

F ood stamp families and individuals Thave a variety of nutrition-related needs, including to increase fruit and vegetable consumption, reduce fat intake, improve food-safety practices and increase skills in cooking, food shopping and utilizing limited resources (Joy and Doisy 1996; West et al. 1999; Murphy et al. 2001). The Food Stamp Nutrition Education Program (FSNEP) has assisted more than 500,000 California families and individuals to improve their dietary well-being since it began in 1994.

Administered by UC, FSNEP provides voluntary nutrition education to families and individuals in 42 California counties. Food stamp clients are enrolled in FSNEP and given 4 to 6 hours of intensive nutrition education in meal planning, food shopping and preparation, food safety and family economics. Major goals of the program include increasing fruit and vegetable consumption, decreasing fat and sugar intake,

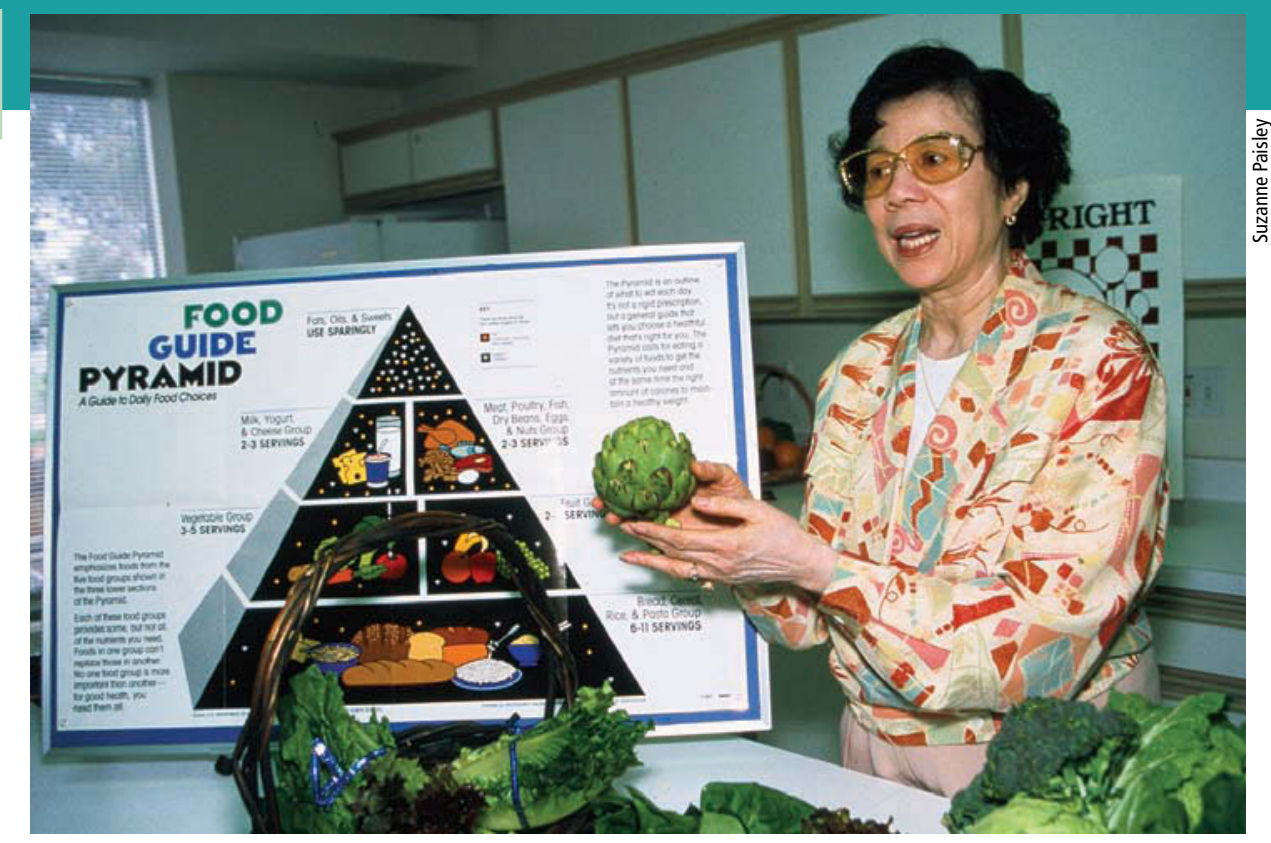

Margaret Fields, program representative for UC Cooperative Extension in Los Angeles County, teaches the USDA food guide pyramid to food stamp clients.

preparing nutritious foods and shopping economically. This paper will focus on the dietary and food behavior skills of FSNEP participants in federal fiscal year 2001-2002 (Joy et al. 2002).

\section{Improvements after FSNEP}

Four dietary behavior measurements were taken in 1,447 clients enrolled in 14 counties (table 1). These results were collected by FSNEP nutrition assistants before FSNEP (pre-test) and then following 4 to 6 hours of nutrition education (post-test) using the Food Behavior Checklist (FBC); the diet-quality questions were validated (Murphy et al. 2001).

The FBC is a 21-item checklist that is self-administered before the nutrition education instruction begins (pre-) and at the end of the last lesson (post-). All enrolled participants are evaluated using the FBC. Each question has five choices (do not do; seldom; sometimes; most of the time; almost always) and pre- and post- results are compared to measure the change in the desired direction. Nine questions are on dietary practices; seven questions are on shopping, planning and preparing food; two questions are on food safety practices; and three questions concern food security.

In our evaluation, the food stamp clients were from a diverse ethnic population: $42.50 \%$ Hispanic, $32.21 \%$ white, $18.12 \%$ black, $1.96 \%$ Native American and $5.21 \%$ Asian. The majority of participating FSNEP clients were female $(82.00 \%)$.

Fruit and vegetable variety are associated with increased consumption of fruits and vegetables, while reducing soda consumption is associated with lowering sugar consumption. Removing chicken skin is associated with decreased fat consumption (Murphy et al. 2001). Mean improvements (range) in the 1,447 FSNEP clients evaluated for vegetable variety were $37.9 \%(21 \%$ to $67 \%)$; for fruit variety, $38.0 \%(11 \%$ to $57 \%$ ); for reduction in soda consumption, $33.3 \%$ (17\% to $48 \%$ ); and for removing chicken skin, $30.8 \%$ ( $11 \%$ to $50 \%$ ). These improvements demonstrate positive behavior changes in the families receiving nutrition education. A decrease in soda consumption together with an increase in fruit and vegetable 


\section{FSNEP offers a variety of simple ideas to help families prepare easy, quick, low-cost and nutritious meals.}

\begin{tabular}{|c|c|c|c|c|c|}
\hline County & Number & $\begin{array}{c}\text { Vegetable } \\
\text { variety }\end{array}$ & $\begin{array}{c}\text { Fruit } \\
\text { variety }\end{array}$ & $\begin{array}{l}\text { Drinking } \\
\text { soda* }\end{array}$ & $\begin{array}{l}\text { Removing } \\
\text { chicken skin } †\end{array}$ \\
\hline Alameda & 171 & 35 & 32 & 33 & 30 \\
\hline Calaveras & 19 & 21 & 11 & 17 & 47 \\
\hline Contra Costa & 65 & 51 & 31 & 42 & 50 \\
\hline Los Angeles & 167 & 39 & 38 & 31 & 32 \\
\hline Placer & 37 & 30 & 41 & 23 & 11 \\
\hline Riverside & 118 & 36 & 32 & 31 & 26 \\
\hline Sacramento & 140 & 40 & 40 & 27 & 38 \\
\hline San Diego & 124 & 31 & 32 & 35 & 21 \\
\hline San Joaquin & 119 & 31 & 41 & 44 & 23 \\
\hline Santa Clara & 50 & 35 & 46 & 42 & 40 \\
\hline Solano & 37 & 49 & 22 & 27 & 22 \\
\hline Sonoma & 7 & 67 & 57 & 57 & 33 \\
\hline Stanislaus & 223 & 42 & 40 & 27 & 31 \\
\hline Tulare & 170 & 40 & 54 & 48 & 36 \\
\hline Total & 1,447 & & & & \\
\hline Mean‡ & & 37.9 & 38.0 & 33.3 & 30.8 \\
\hline
\end{tabular}

TABLE 2. Improvement in food-safety skills in FSNEP participants, as measured by the Food Behavior Checklist

\begin{tabular}{|c|c|c|c|c|}
\hline County & Number & $\begin{array}{l}\text { Foods sit } \\
\text { out* }\end{array}$ & $\begin{array}{l}\text { Thaw } \\
\text { foods* }\end{array}$ & $\begin{array}{c}\text { Food-safety } \\
\text { practices scalet }\end{array}$ \\
\hline & & \multicolumn{3}{|c|}{$\ldots \ldots \ldots \ldots \ldots \ldots \ldots \ldots$} \\
\hline Alameda & 168 & 24 & 29 & 33 \\
\hline Calaveras & 23 & 14 & 22 & 32 \\
\hline Contra Costa & 65 & 37 & 74 & 83 \\
\hline Fresno & 133 & 27 & 40 & 55 \\
\hline Los Angeles & 163 & 26 & 51 & 62 \\
\hline Monterey/SB/SC $¥$ & 40 & 27 & 44 & 46 \\
\hline Placer & 36 & 36 & 42 & 36 \\
\hline Riverside & 118 & 24 & 47 & 57 \\
\hline Sacramento & 144 & 33 & 40 & 53 \\
\hline San Diego & 130 & 41 & 33 & 48 \\
\hline San Joaquin & 144 & 19 & 55 & 60 \\
\hline Santa Barbara & 6 & 33 & 67 & 67 \\
\hline Santa Clara & 51 & 16 & 59 & 65 \\
\hline Solano & 37 & 30 & 49 & 65 \\
\hline Sonoma & 7 & 57 & 86 & 100 \\
\hline Stanislaus & 225 & 25 & 37 & 49 \\
\hline Tulare & 170 & 35 & 52 & 35 \\
\hline Total & 1,660 & & & \\
\hline Mean§ & & 28.0 & 44.3 & 51.1 \\
\hline \multicolumn{5}{|c|}{$\begin{array}{l}\text { * Indicators of good food-safety practices are measured by a decrease in the } \\
\text { number of times food is left out of the refrigerator (foods sit out) and by an } \\
\text { increase in the number of times food is thawed correctly (thaw foods). }\end{array}$} \\
\hline \multicolumn{5}{|c|}{$\begin{array}{l}\text { Food-safety practices score is a combination of FBC questions that look at storing, } \\
\text { preparing and thawing foods. }\end{array}$} \\
\hline \multicolumn{5}{|c|}{ ‡ Monterey, San Benito and Santa Cruz counties. } \\
\hline$\S$ Mean percentage & improvemen & in 1,660 client & & \\
\hline
\end{tabular}

consumption are healthy dietary improvements.

Food-safety skills. FSNEP staff teach safe food-handling and preparation skills, to reduce the incidence of food-borne illnesses. The program offers instruction on a variety of food-safety skills and practices, with a curriculum for low-income populations called "Be Food Safe" (Kaiser 2001). We used the Food Behavior Checklist to measure a number of food-safety skills in 19 FSNEP counties $(n=1,660)$ (table 2). Each of the behaviors evaluated in the checklist are skills taught using the "Be Food Safe" curriculum.

In this population, mean improvements in these skills (range) were: decreased the number of times that food is left out of the refrigerator, $28.0 \%$ (14\% to $57 \%$ ); increased the number of times foods are thawed correctly, $44.3 \%$ (22\% to $86 \%$ ); and overall improvement by increasing the scores in a number of food storage and preparation practices, $51.1 \%$ (32\% to $100 \%$ ). The improvements reported in food-safety practices are important findings, since the incidence of food-borne illness is prevalent in this target population.

Economical food practices. Two counties (Los Angeles and Merced) collected 24-hour food-recall data on the amount of money spent on food before and after receiving FSNEP instruction. The 24-hour food-recall is an evaluation instrument that collects data on an individual's food consumption over a 24-hour time period. In Los Angeles County, recalls were collected on 167 FSNEP participants before (pre-) and after (post-) receiving nutrition education instruction. These participants are different from the ones reported in tables 1 and 2 .

In Merced County, 293 participants re- ceived nutrition education instruction by the Home Study method. In this delivery method, the first lesson is taught face to face and the rest of the materials (five lessons) are sent to the enrolled participant in the mail. The staff member contacts the enrolled participant by telephone to answer questions. The recall was done face to face (pre-) and then by telephone (post-). The Home Study method has been evaluated and is an effective approach to teaching families who are in remote locations (Lamp et al. 1999).

\section{A FSNEP success story}

I recently saw a former client at a local Asian restaurant. She is a tall, stately woman and was accompanied by her children, a grandmother and another friend with her children. She remembered me from a FSNEP class held at the local women's shelter more than 7 years earlier. Since then, Hope (not her real name) had gotten her own place and become a counselor for a local substanceabuse program. She had been sharing nutrition information from my FSNEP classes, and told me how much the information had helped her. She asked if I would come and expand on those classes for her clients. It was gratifying to network with a former client who thought enough of FSNEP to share that information as well as ask me to educate others under her counsel. Hope and I now have a continuing working bond, as well as a personal one. I am very proud of this former client, who managed to pull resources together and move away from substance abuse and help other women. She has come a long way since our initial contact in FSNEP.

$$
\text { - Carolyn Gavranich, FSNEP Nutrition Education Assistant, Placer County }
$$




\begin{tabular}{|c|c|c|c|c|}
\hline \multicolumn{5}{|c|}{$\begin{array}{l}\text { TABLE 3. Amount of money spent on food in FSNEP clients, } \\
\text { Los Angeles and Merced counties }\end{array}$} \\
\hline \multirow[b]{2}{*}{ County } & \multirow[b]{2}{*}{ Number } & \multicolumn{2}{|c|}{ Money spent on food } & \multirow[b]{2}{*}{ Change* } \\
\hline & & Pre-test & Post-test & \\
\hline & & $\ldots \ldots$ & $\cdots$ & $\%$ \\
\hline Los Angeles & 167 & 85.10 & 72.40 & -14.9 \\
\hline Merced & 293 & 59.40 & 51.70 & -15.0 \\
\hline
\end{tabular}

TABLE 4. Dietary changes in FSNEP clients, Los Angeles and Merced counties

\begin{tabular}{|c|c|c|c|c|}
\hline County & Number & Pre-test* & Post-test & Changet \\
\hline & \multicolumn{4}{|c|}{$\ldots \ldots \ldots$ servings $\ldots \ldots \ldots$} \\
\hline Los Angeles & 167 & 1.1 (fruit) & 1.5 (fruit) & +0.4 \\
\hline Los Angeles & 167 & 1.4 (other) & 1.0 (other) & -0.4 \\
\hline Merced $\ddagger$ & 293 & 1.2 (dairy) & 1.4 (dairy) & +0.2 \\
\hline \multicolumn{5}{|c|}{$\begin{array}{l}\text { * Servings were calculated by scoring the number of fruit, vegetable, dairy and "other" } \\
\text { (high-fat, high-sugar) foods reported in } 24 \text {-hour recalls before and after receiving } \\
\text { nutrition education lessons. }\end{array}$} \\
\hline \multicolumn{5}{|l|}{$+P<0.05$} \\
\hline ‡ Used Home & livery $n$ & & & \\
\hline
\end{tabular}

In both counties, the results showed significant improvements in money saved on food purchases and in consumption of fruit and dairy products, and decreases in the consumption of nonnutritious foods (tables 3 and 4).

In urban Los Angeles County, the amount of money spent on food decreased by $14.9 \%(P<0.05)$. In these same participants, fruit consumption increased by 0.4 servings and "other" foods (a measure of the consumption of nonnutritious foods) decreased by 0.4 servings. Both these behavior changes

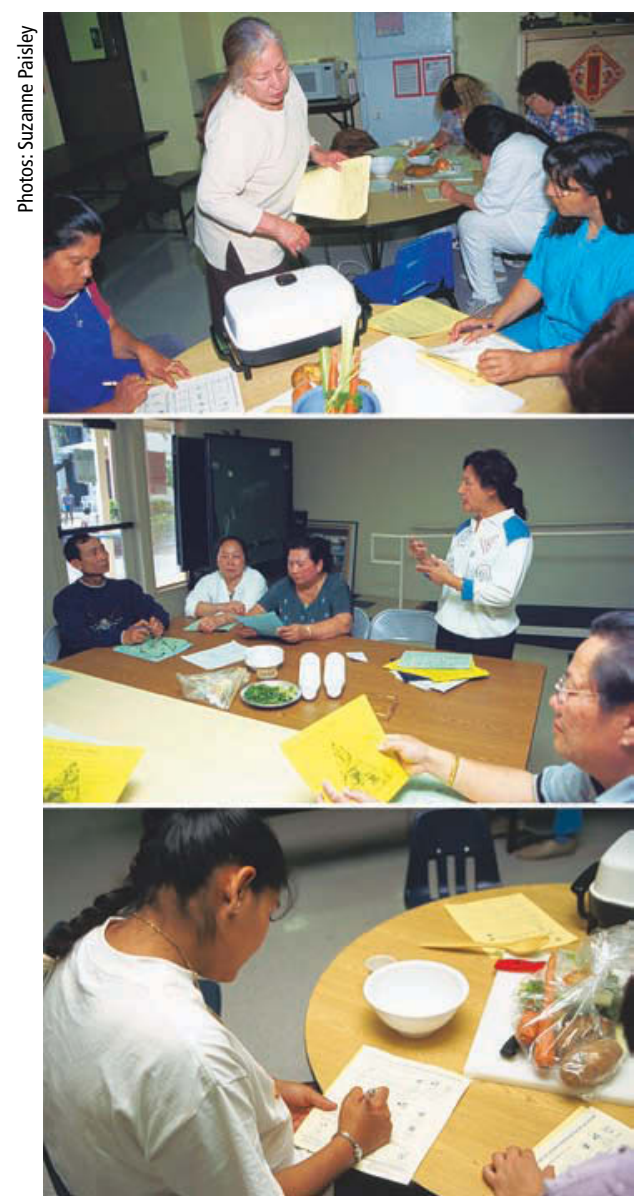

Nutrition education assistants provide lessons on nutrition, food safety and food preparation as part of the Food Stamp Nutrition Education Program, which serves about 50,000 people annually in California. were significant $(P<0.05)$. Other dietary changes were not significant.

In primarily rural Merced County, the amount of money spent on food decreased by $15 \%(P<0.05)$. In these same participants, dairy product consumption (a measure of calcium intake) increased by 0.2 servings $(P<0.05)$. Other dietary changes were not significant.

\section{Future programming}

These dietary and economic food practices and food-safety results are presented annually to all FSNEP staff for two purposes: to identify the nutritional needs of FSNEP clients and provide feedback on staff teaching results. FSNEP staff use a variety of teaching methods to motivate clients to change their behavior. For example, telling participants that hand-washing is important does not make the point as well as the "glitter gel" demonstration, which shows that "germs" can rapidly spread among people and food. In this exercise, one participant rubs a little gel on his or her hand. After a short time participating in another activity, all participants can see the glitter on everything and everyone else. This type of teaching has a dramatic impact on participants who now clearly want to wash their hands.

FSNEP offers a variety of simple ideas to help families prepare easy, quick, lowcost and nutritious meals. Results from a study on the food-preparation practices of low-income families showed that these families lack cooking skills yet are interested in learning how to prepare nutritious meals for their families (West 1999; Joy et al. 1999). Currently, the "learner-centered" educational approach is being used in FSNEP to make sure that the needs of the clients are at the center of the educational program.

The evaluation results have helped the program staff to better understand the needs of the target audience. We want to assist our clients to improve their diets for two reasons: first, by helping them to understand the importance of a healthy diet to reduce their risk of chronic disease, and second by convincing them that a healthy diet can be lowcost and delicious.

A.B. Joy is Academic Specialist, Department of Nutrition, UC Davis. Chris Hanson provided statewide data analysis, and William Benford provided demographic and individual county analysis. FSNEP county management was provided by Mary Blackburn, Gloria Espinoza-Hall, Nancy Feldman, Mary Fujii, Chutima Ganthavorn, Linda Garcia, Jan Harwood, Sharon Junge, Cathi Lamp, Martha Lopez, Anna Martin, Diane Metz, Yvonne Nicholson, Carol Powell, Jeanette Sutherlin, Patti Wooten Swanson, Barbara Turner, Estella West and Martha Weston. Beverly Benford provided administrative coordination. Funding for this study was provided by the U.S. Department of Agriculture through the California Department of Social Services.

\section{References}

Joy $A B$, Benford B, Benford W, Hanson C. 2002. FSNEP Final Report to the USDA for Fiscal Year 2001/2002. UC Davis.

Joy AB, Doisy C. 1996. Food Stamp Nutrition Education Program: Assisting food stamp recipients to become more selfsufficient. J Nutrition Ed 28:123-6.

Joy AB, Feldman N, Fujii ML, et al. 1999. Food stamp recipients eat more vegetables after viewing nutrition videos. Cal Ag 53(5):24-8.

Kaiser L. 2001. Be Food Safe - Curriculum for FSNEP/EFNEP. UC DANR Pub 5400. Oakland, CA.

Lamp C, George J, Wright J, Joy AB. 1999. The use of home study to improve nutrition knowledge in two rural counties of California. J Nutrition Ed 31:94-8.

Murphy SP, Kaiser LL, Townsend MS, Allen LH. 2001. Evaluation of validity of items for a food behavior checklist. J Am Dietetic Assoc 101:751-6.

West E, Lamp C, Joy AB, et al. 1999. Food preparation practices influence nutrition. Cal Ag 53(1):29-32. 